Full length article

\title{
Ectopic tissue engineered ligament with silk collagen scaffold for ACL regeneration: A preliminary study
}

\author{
Jisheng Ran ${ }^{\mathrm{a}, \mathrm{c}, 1}$, Yejun $\mathrm{Hu}^{\mathrm{a}, \mathrm{b}, 1}$, Huihui Le ${ }^{\mathrm{a}, \mathrm{c}}$, Yangwu Chen ${ }^{\mathrm{a}, \mathrm{b}, \mathrm{c}}$, Zefeng Zheng ${ }^{\mathrm{a}}$, Xiao Chen ${ }^{\mathrm{b}, \mathrm{f}}$, Zi Yin ${ }^{\mathrm{b}}$, \\ Ruijian Yan ${ }^{a, c}$, Zhangchu Jin ${ }^{a, b, c}$, Chenqi Tang ${ }^{a, b, c}$, Jiayun Huang ${ }^{a, b, c}$, Yanjia Gu ${ }^{\text {a,b,c }}$, Langhai Xu ${ }^{\text {a,c }}$, \\ Shengjun Qian ${ }^{\mathrm{a}, \mathrm{c}}$, Wei Zhang ${ }^{\mathrm{a}, \mathrm{c}}$, Boon Chin Heng ${ }^{\mathrm{d}}$, Pioletti Dominique ${ }^{\mathrm{e}}$, Weishan Chen ${ }^{\mathrm{a}, \mathrm{c}}$, Lidong $\mathrm{Wu}^{\mathrm{a}, \mathrm{c}}$, \\ Weiliang Shen ${ }^{\mathrm{a}, \mathrm{b}, \mathrm{c}, \mathrm{f}, *}$, Hongwei Ouyang ${ }^{\mathrm{b}, \mathrm{f}}$ \\ a Department of Orthopedic Surgery, The Second Affiliated Hospital, School of Medicine, Zhejiang University, Hangzhou, People's Republic of China \\ ${ }^{\mathrm{b}}$ Dr. Li Dak Sum and Yip Yio Chin Center for Stem Cells and Regenerative Medicine, School of Medicine, Zhejiang University, Hangzhou, People's Republic of China \\ 'Orthopaedics Research Institute of Zhejiang University, Hangzhou, People's Republic of China \\ ${ }^{\mathrm{d}}$ Department of Endodontology, Faculty of Dentistry, The University of Hong Kong, Pokfulam, Hong Kong \\ e Laboratory of Biomechanical Orthopedics, EPFL, Lausanne, Switzerland \\ ${ }^{\mathrm{f}}$ China Orthopaedic Regenerative Medicine (CORMed), Hangzhou, China
}

\section{A R T I C L E I N F O}

\section{Article history:}

Received 25 October 2016

Received in revised form 2 February 2017

Accepted 13 February 2017

Available online 16 February 2017

\section{Keywords:}

ACL regeneration

Ectopic tissue engineered ligament

Silk collagen scaffold

Bone tunnel healing

\begin{abstract}
A B S T R A C T
Anterior cruciate ligament $(\mathrm{ACL})$ reconstruction remains a formidable clinical challenge because of the lack of vascularization and adequate cell numbers in the joint cavity. In this study, we developed a novel strategy to mimic the early stage of repair in vivo, which recapitulated extra-articular inflammatory response to facilitate the early ingrowth of blood vessels and cells. A vascularized ectopic tissue engineered ligament (ETEL) with silk collagen scaffold was developed and then transferred to reconstruct the ACL in rabbits without interruption of perfusion. At 2 weeks after ACL reconstruction, more wellperfused cells and vessels were found in the regenerated ACL with ETEL, which decreased dramatically at the 4 and 12 week time points with collagen deposition and maturation. ACL treated with ETEL exhibited more mature ligament structure and enhanced ligament-bone healing post-reconstructive surgery at 4 and 12 weeks, as compared with the control group. In addition, the ETEL group was demonstrated to have higher modulus and stiffness than the control group significantly at 12 weeks post-reconstructive surgery. In conclusion, our results demonstrated that the ETEL can provide sufficient vascularity and cellularity during the early stages of healing, and subsequently promote ACL regeneration and ligament-bone healing, suggesting its clinic use as a promising therapeutic modality.
\end{abstract}

\section{Statement of Significance}

Early inflammatory cell infiltration, tissue and vessels ingrowth were significantly higher in the extraarticular implanted scaffolds than theses in the joint cavity. By mimicking the early stages of wound repair, which provided extra-articular inflammatory stimulation to facilitate the early ingrowth of blood vessels and cells, a vascularized ectopic tissue engineered ligament (ETEL) with silk collagen scaffold was constructed by subcutaneous implantation for 2 weeks. The fully vascularized TE ligament was then transferred to rebuild ACL without blood perfusion interruption, and was demonstrated to exhibit improved ACL regeneration, bone tunnel healing and mechanical properties.

(c) 2017 Published by Elsevier Ltd on behalf of Acta Materialia Inc.
* Corresponding author at: Department of Orthopedic Surgery, 2nd Affiliated Hospital, School of Medicine, Zhejiang University, 88 Jie Fang Road, Hangzhou 310009, China.

E-mail address: shenweiliang365@163.com (W. Shen).

1 These co-authors contributed equally to the work.

\section{Introduction}

As a main stabilizing structure of the knee, the anterior cruciate ligament $(A C L)$ is one of the most commonly injured ligaments during sports and other strenuous physical activities [1]. Because of the unsatisfactory outcomes of conservative treatment modalities, ACL reconstructive surgery is now considered the treatment 
of choice in the majority of clinical cases [2,3]. Despite the drawbacks of various different types of grafts, such as autograft donor site morbidity, potential disease transmission with allografts and the lack of biodegradability of synthetic materials [4,5], the difficulty of achieving revascularization and subsequent delayed ligamentization are major obstacles to restoring normal joint function in the clinic [6-8]. Hence, the regeneration of a functional ACL, with its dynamic fluid environment and inherent lack of blood supply and endogenous cells within the joint cavity, is extremely challenging.

In recent years, tissue engineering (TE) has delivered promising results that might overcome these challenges [9]. Biological materials, biodegradable polymers and composite materials have been developed in ACL reconstruction [9,10]. Amongst these, silkbased biomaterials have been intensively studied, due to their good biocompatibility, mechanical strength and controllable biodegradability [11]. To date, silk-based biomaterials have achieved promising results in the repair of injured Achilles tendon [12], medial collateral ligament (MCL) [13] and shoulder rotator cuff tendon [14]. Based on the promising outcomes of extraarticular tendon/ligament regeneration, the silk scaffold was also applied in ACL reconstruction in rabbits and there was observed to be functional ACL regeneration and osteoarthritis (OA) improvement in the long term [15]. However, the lack of inflammatory response, vascularization and adequate cell numbers during the early stage of ACL regeneration, which leads to a prolonged regenerative process and lack of mechanical support during the early stage, still present an exigent issue to be resolved.

Vascularization is a key process in tissue engineering, particularly for massive tissue repair of the avascular environment of a host site like ACL $[16,17]$. Various attempts have been made to generate a functional vasculature in recent years, including biochemical modification [18-21], exogenous cells [10,22-24], and microengineering technology [25-30]. Most of these attempts, however, have only focused on applying exogenous vascular cells and angiogenic factors. Recently, the fundamentals of the proper endogenous immune system response in vascular formation and adaptation is being increasingly recognized [31-33]. Many types of immune cells have been demonstrated to function in early vascular formation. Amongst these, macrophages have been intensively studied and are thought to be one of the most important cell types involved in this process, because it can produce and secrete various bioactive molecules, including vascular endothelial growth factor (VEGF), transforming growth factor-beta (TGF- $\beta$ ), basic fibroblast growth factor (bFGF), platelet derived growth factor-BB (PDGF-BB), tumor necrosis factor (TNF), and various cytokines of the Interleukin (IL) family such as IL-6, IL-10 and IL17 [34-37]. These factors play critical roles in controlling neovascularization and vascular remodeling, as well as the regenerative response by promoting tissue-endogenous adult stem cell proliferation $[37,38]$. Depletion of macrophages have been proven to be detrimental to vascular formation and wound healing [39,40]. Hence, the recapitulation of a proper early inflammatory response and endogenous repair processes, particularly macrophage recruitment and activation, may be an effective strategy to enhance vascularization in tissue engineering.

In this study, we demonstrated that early inflammatory cell infiltration and angiogenic factor gene expression were significantly higher in the subcutaneously implanted silk collagen scaffolds than the intra-articular implanted scaffolds, which was correlated with faster and better vascularization and tissue ingrowth. Hence, we developed a new strategy to mimic the early stages of wound repair, which provided extra-articular inflammatory stimulation to facilitate the early ingrowth of blood vessels and cells. A vascularized ectopic tissue engineered ligament (ETEL) with silk collagen scaffold was constructed by subcutaneous implantation for 2 weeks. The fully vascularized TE ligament was then transferred with one end free, as a flap, to rebuild the ACL in rabbits without interruption of blood perfusion. ACL regeneration, ligament-bone integration and mechanical properties were subsequently evaluated.

\section{Materials and methods}

\subsection{Scaffold fabrication}

Raw silk fibers (Bombyx mori) were purchased from Zhejiang Cathaya International Inc. (Hangzhou, China). The silk collagen sponge scaffold was fabricated as described previously [13]. Briefly, the knitted silk was fabricated using 19 yarns (1 filament/yarn) of silk fibers on a knitting machine. The pore size was approximate $0.4 * 0.4 \mathrm{~mm}$. The knitted silks were treated with an aqueous solution containing $0.02 \mathrm{M} \mathrm{Na}_{2} \mathrm{CO}_{3}$ at $90{ }^{\circ} \mathrm{C}$ and $100{ }^{\circ} \mathrm{C}$ for $60 \mathrm{~min}$ to extract the sericin. Insoluble type I collagen was isolated and purified from pig Achilles' tendon using neutral salt and dilute acid extractions as described previously [41]. Briefly, pig Achilles's tendon was separated, cut into pieces and washed, followed by incubation in $0.5 \mathrm{M}$ acetic acid (HAc) ( $\mathrm{pH} 2.5)$ at $4{ }^{\circ} \mathrm{C}$ for $16 \mathrm{~h}$. Then the tendon was briefly homogenized and subjected to centrifugation at $22,000 \mathrm{~g}$ at $4{ }^{\circ} \mathrm{C}$ for $15 \mathrm{~min}$. Stepwise extraction of collagen was carried out, followed by washing in $0.1 \mathrm{M} \mathrm{NaCl}, 0.05 \mathrm{M}$ Tris- $\mathrm{HCl}(\mathrm{pH}$ 7.2) with $20 \mathrm{mM}$ ethylene diamine tetra acetic acid (EDTA) and $2 \mathrm{mM}$ N-ethylmaleimide (NEM) for 3 days, $1.0 \mathrm{M} \mathrm{NaCl}, 0.05 \mathrm{M}$ Tris $-\mathrm{HCl}(\mathrm{pH} 7.2)$ with $20 \mathrm{mM}$ EDTA and $2 \mathrm{mM}$ NEM for 5 days, $0.5 \mathrm{M} \mathrm{HAc}(\mathrm{pH} 2.5$ ) with $4 \mathrm{M}$ urea and $2 \mathrm{mM}$ NEM for 1 day, $0.5 \mathrm{M}$ HAc (pH 2.5) with $2 \mathrm{mM}$ NEM for 3 days, demineralized water for 2 days, acetone for 4 days and finally water for the last 3 days. For all steps, the buffer was changed daily and centrifugation at $22,000 \mathrm{~g}\left(4^{\circ} \mathrm{C}\right)$ for $15 \mathrm{~min}$ was performed to recover the collagen. All reagents used above were purchased from Sigma-Aldrich (St. Louis, MO, USA). Purified collagen was lyophilized afterwards. The sericin-extracted knitted silk mesh (Fig. S1A) was immersed in an acidic collagen solution (type $\mathrm{I}, \mathrm{pH} 3.2,1 \mathrm{wt} \%, 3 \mathrm{~mm}$ depth), and frozen at $80^{\circ} \mathrm{C}$ for $12 \mathrm{~h}$. It was then freeze-dried under vacuum (Heto PowerDry LL1500) for 48 h to allow the formation of collagen sponges. Then the scaffolds were cross-linked by dehydrothermal treatment and cut into two different sizes at $0.5 \mathrm{~cm} * 0.5 \mathrm{~cm}$ for the first stage animal experiments and $1 \mathrm{~cm} * 8 \mathrm{~cm}$ for the second stage animal experiments (see below) (Fig. S1B).

The "sandwich-like" structure of the scaffold, with knitted silk incorporated between two layers of collagen sponge, was demonstrated by a scanning electron microscope (SEM). (Fig. S1C) To accomplish the SEM test, the specimens were dehydrated in increasing concentrations of alcohol (30\% to $100 \% \mathrm{v} / \mathrm{v}$ ) and were critically point-dried. These were then mounted on aluminum stubs and coated with gold, and viewed under a Hitachi S-3000 N SEM at an accelerating voltage of $15 \mathrm{kV}$.

\subsection{Animal experiment}

Forty-eight New Zealand White rabbits weighing $2.5-3.0 \mathrm{~kg}$ were utilized for this study. The animals were subjected to general anesthesia, skin preparation and disinfection according to standard surgical protocols. Two stages of animal experiments were carried out in this study.

In the first stage, subcutaneous and intra-articular environment were compared. Twenty-four rabbits were used in this stage. The knitted silk collagen scaffolds were immersed in sterile phosphate buffered solution (PBS) before implantation. Anterior midline skin incision and lateral parapatellar arthrotomy [42] were used to expose the subcutaneous cavity and to open the knee joint cavity 
in one leg respectively. The scaffolds were then implanted subcutaneously and intra-articularly. The incision was sutured layer by layer up to the skin surface. At 3 days, 1, 2 and 4 weeks after implantation, the animals were sacrificed and the scaffolds were explanted for further evaluation.

In the second stage, ACL reconstruction was conducted to compare the effect of ETEL and silk collagen scaffold in the rest twentyfour rabbits. Subcutaneous implantation was performed in a similar procedure above, with one side tightly ligated to the lower part of the patellar ligament and the other side anchored to the subcutaneous fascia in the left leg. Two weeks after implantation, the scaffold was carefully separated from the distal end with the proximal end reserved. Lateral parapatellar arthrotomy was used to expose the knee joint of the rabbit. After the native ACL excision, the tibial and femoral bone tunnels were created with a $3.0 \mathrm{~mm}$ diameter drill-bit. The vascularized ETEL was carefully pulled trough the bone tunnel and fixed with 2-0 polyester suture (MERSILK, Johnson \& Johnson, US) in a whipstitch style. For the control group, the simple silk collagen scaffold was rolled up along the short axis and passed through the tunnel with both ends fixed. The incision was then closed layer by layer up to the skin. After surgery, animals were allowed free cage activity. Upon animal sacrifice, three limbs from each experimental group were utilized for histological evaluation and gene expression analysis at the 2, 4 and 12 weeks time points, 3 additional limbs from each group were subjected to mechanical test at 12 weeks. Specimens were imaged by transmission electron microscopy (TEM) to assess the collagen fibril diameter after 2, 4 and 12 weeks post-surgery, and were scanned with MRI and microCT at the 12 weeks time point. Treatment of animals was in accordance with standard guidelines approved by the Ethics Committee of the second affiliated hospital, school of medicine, Zhejiang university (Ethical approval number: 2015-401).

\subsection{Macroscopic and histological assessment}

Specimens were fixed with $4 \%$ paraformaldehyde, decalcified with $10 \%$ EDTA, gradiently dehydrated, and embedded within paraffin blocks. Histological sections $(7 \mathrm{~mm}$ ) were prepared using a microtome, and subsequently deparaffinized with xylene, hydrated using decreasing concentrations of ethanol, and then subjected to hematoxylin and eosin (HE) staining, Masson trichrome and safranin $\mathrm{O}$ (SO) staining. Histological scoring of ACL repair was performed by two people using a blinded semiquantitative scoring system based on six parameters (fiber structure, fiber arrangement, rounding of nuclei, vascularity, inflammation, cell population) of HE staining. Every parameter was graded from 0 to 3 , with 0 being normal and 3 being maximally abnormal [43].

\subsection{Collagen content assay}

The amount of deposited collagen on the scaffold was quantified by using a collagen quantitative assay kit (Jiancheng Inc., Nanjing, China) following the manufacturer's protocol [13].

\subsection{RNA isolation and real time polymerase chain reaction (RT-PCR)}

Total tissue RNA was isolated by lysis in TRIZOL (Invitrogen Inc., Carlsbad, CA, USA) followed by a one-step phenol chloroformeisoamyl alcohol extraction as described by the manufacturer's protocol. Real-time PCR analysis of seven genes including CD86, ARGINASE-1 (ARG-1), vascular endothelial growth factor (VEGF), COLLAGEN I (COL I), TENASCIN (TNC), COLLAGEN III (COL III) and GAPDH was performed using Brilliant SYBR Green QPCR Master Mix (TakaRa) with a Light Cycler apparatus (ABI STEPONE
PLUS), as described previously [44]. The primer sequences used in this study are listed in Table 1. Each real-time PCR run was performed with at least three experimental replicates, and the results are presented as target gene expression normalized to GAPDH.

\subsection{Immunohistochemistry}

A series of $7 \mathrm{~mm}$-thick sections were utilized for immunohistochemical staining (IHC). Endogenous peroxidase was firstly blocked with hydrogen peroxide before pepsin treatment for $20 \mathrm{~min}$. Mouse anti-rabbit monoclonal antibodies against $\alpha$-smooth muscle actin ( $\alpha$-SMA) (1:200 dilution; BOSTER Inc., Wuhan, China) and CD14 (1:200 dilution; BOSTER Inc., Wuhan, China) were used to detect the presence of blood vessels and inflammatory cell infiltration in the subcutaneously implanted scaffold and the repaired ACL respectively. Monoclonal antibodies were applied for $1 \mathrm{~h}$ followed by incubation with biotinylated goat anti-mouse antibody (Lab Vision Corporation, CA) for $30 \mathrm{~min}$. Streptavidin peroxidase was added for $45 \mathrm{~min}$ and 3,30diaminobenzidine was used as a chromogenic agent.

\subsection{Transmission electron microscopy (TEM)}

Tissue specimens at the 2- and 12-weeks time points from each group were fixed following the standard procedures for TEM to assess collagen fibril diameter within the regenerated ACL. Specimens were pre-fixed with $2 \%$ glutaraldehyde for $24 \mathrm{~h}$ and washed twice with PBS followed by post-fixation treatment with $1 \%$ osmic acid for $2 \mathrm{~h}$. After two washes in PBS, the specimens were dehydrated in ethanol gradient $(50 \%, 70 \%, 80 \%, 90 \%$, and 3 changes of $100 \%$ ). Propylene oxide was used as a transitional solvent. The specimens were infiltrated in a 1:2 mixture of EponAraldite embedding resin and propylene oxide for $24 \mathrm{~h}$, followed by a $1: 1$ mixture of resin and propylene oxide for $24 \mathrm{~h}$, and a $2: 1$ mixture of resin and propylene oxide. Finally, the specimens were infiltrated in $100 \%$ Epon-Araldite using molds for $48 \mathrm{~h}$ at $60{ }^{\circ} \mathrm{C}$. The embedded specimens were thin sectioned $(70 \mathrm{~nm})$ and viewed under TEM (Quanta 10 FEI). Approximately 500 collagen fibrils were imaged and measured for each sample to obtain an accurate representation of the fibril diameter distribution, using image analysis software (Image-Pro Plus, Rockville, MD, USA).

\subsection{MicroCT}

For microCT observations, specimens were first fixed with $4 \%$ $(\mathrm{w} / \mathrm{v})$ paraformaldehyde for 2 days. Subsequently, specimens from each group (12 weeks) were scanned with a MicroCT imaging system with an $18 \mathrm{~mm}$ isotropic voxel resolution under $60 \mathrm{kV}$ scanning voltage (Skyscan1076, Micro Technology, Hong Kong).

\subsection{Magnetic resonance imaging (MRI)}

Before MRI analysis, the rabbits were subjected to general anesthesia at 12 weeks post-reconstruction. The MRI images were acquired by a 3.0T MRI imaging system (Siemens, Germany), with the parameters being set and the process being conducted by an experienced engineer. T2 phase (or T2-weighted imaging, T2WI) was used to assess the bone tunnel healing and articular fluid distribution. The parameters were set as follows: repetition time $(\mathrm{TR})=3000 \mathrm{~ms}$, echo time $(\mathrm{TE})=100 \mathrm{~ms}$, scanning slice thickness $=2 \mathrm{~mm}$.

\subsection{Mechanical evaluation}

Mechanical testing was performed using an Instron tension/ compression system with Fast-Track software (Model 5543, 
Table 1

Primer sequences of selected genes utilized in this study for RT-PCR.

\begin{tabular}{lll}
\hline Gene Name & Forward Primer & Reverse Primer \\
\hline GAPDH & TCACCATCTTCCAGGAGCGA & CACAATGCCGAAGTGGTCGT \\
CD86 & CAGATCAAGGACAAGGGCGT & CCTTGTACAGACGAGCAGGT \\
ARG-1 & GCTGTCATTTGGGTGGATGC & CCTTGGCAGATATGCAGGGA \\
VEGF & ACCGAGGAGTTCAACGTCAC & AGCTCATCTCCCCTATGTC \\
Col 1a1 & CGATGGCTTCCAGTTCGAGT & GCTACGCTGTTCTTGCAGTG \\
Col 3a1 & GTTCTGGAGGATGGCTGCTC & TCACAGCCTTGCGTGTTCTA \\
TNC & CATCCGGCACAAACGACAG & CATCCGGCACAAACGACAG \\
\hline
\end{tabular}

Instron, Canton, MA). For ACLs, both hindlimbs were disarticulated at the hip joint, wrapped in saline-soaked gauze, immediately packed in plastic bags, and stored at $-20^{\circ} \mathrm{C}$. Before biomechanical testing, the frozen, saline-soaked specimens were thawed at room temperature. The ACLs were prepared with attached femoral and tibial bone blocks, leaving the insertion sites intact. The specimens were then dissected free of all soft tissue except the ACL, leaving a femur-ACL-tibia complex (FATC).

The FATCs were then rigidly fixed to custom-made clamps to align the collagen fibers. After applying a pre-load of $3 \mathrm{~N}$, each FATC underwent pre-conditioning by cyclic elongation between 0 and $0.75 \mathrm{~mm}$ for 3 cycles at $5 \mathrm{~mm} / \mathrm{min}$. This was followed by load to failure testing at an elongation rate of $5 \mathrm{~mm} / \mathrm{min}$. The loadelongation behavior of the FATCs and failure modes were recorded. The structural properties of the FATC were represented by stiffness $(\mathrm{N} / \mathrm{mm})$, maximal load $(\mathrm{N})$ and modulus $(\mathrm{MPa})$.

\subsection{Statistical analysis}

All quantitative data sets are expressed as mean \pm SD. Student's $t$-test was performed to assess statistically significant differences in the results of different experimental groups. All statistical data were analyzed by the IBM SPSS Statistics software 19.0. Values of $\mathrm{p}<0.05$ were considered to be significantly different.

\section{Results}

3.1. Subcutaneous implantation of SCSs enhanced vascularization and promoted more cell and tissue ingrowth than intra-articular implantation, which correlates with increased infiltration of CD14 positive cells and inflammatory response

To compare the early inflammatory response between the subcutaneous and intra-articular microenvironment during tissue engineering, we first implanted the silk collagen scaffolds within the rabbit subcutaneous pocket and knee joint cavity for up to 4 weeks. HE staining demonstrated that cellular and neo-tissue ingrowth was slow in the intra-articular scaffolds. In contrast, however, large numbers of cells and abundant matrix deposition were found in the subcutaneous scaffolds at 1 week post implantation. (Fig. 1A, D). The expression of extracellular matrix (ECM) related genes such as col 1 was also significantly higher in the subcutaneous group at 1 week post-implantation (Fig. 1J). Immunohistochemical (IHC) staining revealed that CD14 positive monocyte/macrophage infiltration inside the scaffold was significantly higher in the subcutaneous group, compared with the intra-articular group. (Fig. 1B, red arrow; E) As there are few antibodies available to distinguish the macrophage subtypes of rabbits, RT-PCR analysis of CD86 and arginase 1 (ARG-1) gene expression was chosen as an alternative to detect M1 and M2 macrophages, respectively. The RT-PCR result showed higher expression of CD86 genes in the subcutaneous group, as compared to the intraarticular group at day 3, week 1 and week 2 post-reconstruction (Fig. 1G). The expression level of ARG-1, however, was not significantly different between the two groups in all time points (Fig. 1H). Furthermore, the pro-angiogenic factor VEGF, which was thought to be mainly produced by macrophages, was also detected by RT-PCR and resulted in significantly higher expression in the subcutaneous group at 1 week post-implantation (Fig. 1I). Finally, the blood vessel density was demonstrated to be significantly higher in the subcutaneously implanted scaffold by IHC staining against a-SMA (Fig. 1C, F). Hence, we demonstrated that the inflammatory response profile in the joint cavity was apparently different from that subcutaneously, which was correlated with significantly lesser neo-tissue ingrowth and slower regeneration.

\subsection{Ectopic tissue engineered ligament (ETEL) was constructed by subcutaneous implantation of silk-collagen scaffolds for 2 weeks before further ACL reconstruction}

Based on the aforementioned previous results, we hypothesized that ectopic implantation of the silk collagen scaffold in the subcutaneous pocket could mimic the early stages of repair and develop a highly vascularized and multicellular tissue engineered ligament, which could be grafted to surgically reconstruct the ACL without interruption of perfusion by the flap technique. Since there was more cellularity and vascularity at the 2 weeks timepoint (Fig. 1A-E, G), subcutaneous implantation of the silk-collagen scaffolds for 2 weeks was chosen to develop the highly vascularized ectopic-engineered ligament.

After two-weeks post subcutaneous implantation, the ectopic tissue engineered ligament showed a pink appearance with rich blood supply, which was carefully separated from the distal end while the proximal end was retained and the adjacent vascular network connection was fully protected (Fig. 2Ab, Bb arrow). After opening the joint cavity, the native ACL was completely removed and a bone tunnel was drilled into the tibia and femur (Fig. 2Ac, $\mathrm{Bc})$. Then the distal end of the ETEL was pulled through the bone tunnel gently and fixed (Fig. 2Ad, Bd). In the control group, a simple silk collagen scaffold without subcutaneous implantation was used to reconstruct the ACL by a similar procedure (Fig. 2Ae, Be). At 2, 4 and 12 weeks after ACL reconstruction, the animals were sacrificed for further evaluation (Fig. 2C).

\subsection{ETEL promoted ACL regeneration with better tendinous properties}

No necrotic or inflammatory tissue was found at all time-points in the ETEL group, thus indicating that the blood flow in the graft was patent without obvious obstruction (Fig. 3A, B). Gross morphology revealed that the ETEL was covered with regenerated fibrous tissues and the silk fibers could not be clearly discerned at all time-points. By contrast, less fibrous tissue ingrowth was observed in the SCS group, which resulted in a fuzzy appearance. (Fig3A)

The histology of the ETEL groups showed that denser connective tissues filled and wrapped the scaffold (Fig. 3B). At 2 weeks post-implantation, abundant blood vessels and spindle tendonlike cells were present within the regenerated tissues around the scaffold in the ETEL group, whereas there were few cells or angiogenesis in the SCS group (Fig. 3B, D). At 4 and 12 weeks post-reconstruction, the blood vessel and cell numbers decreased gradually in the ETEL group, along with the elongation of tendon-like cells and increased ECM deposition. The SCS group, however, exhibited insufficient repair tissues with the absence of repair at some sites, although the cell numbers and blood vessels increased at 4 and 12 weeks post-reconstruction (Fig. 3B, D, E, F). Additionally, the histological score of the ETEL group was significantly lower than the SCS group at all time-points, indicating improved regeneration of the ACL (Fig. 3G). 

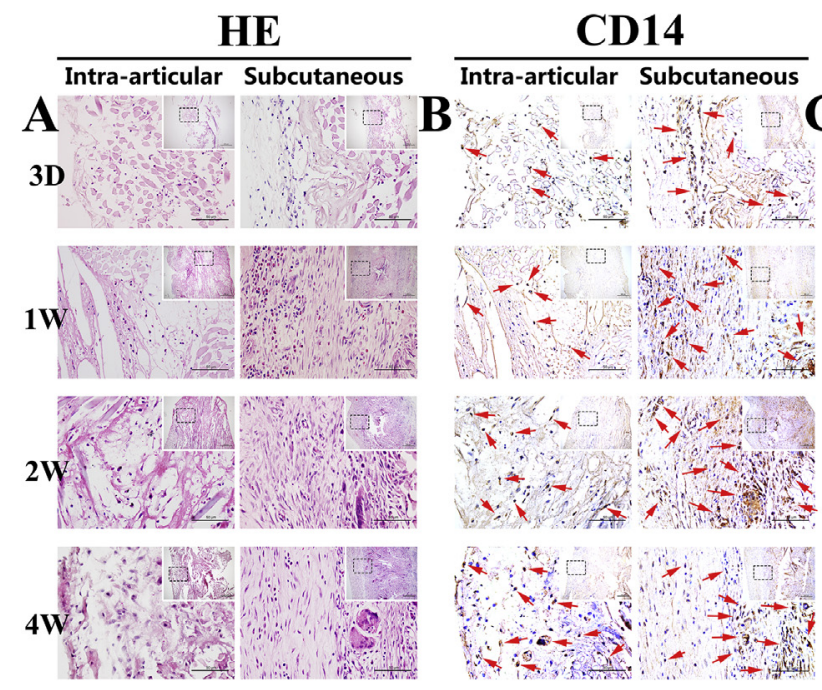

\section{Q-SMA}
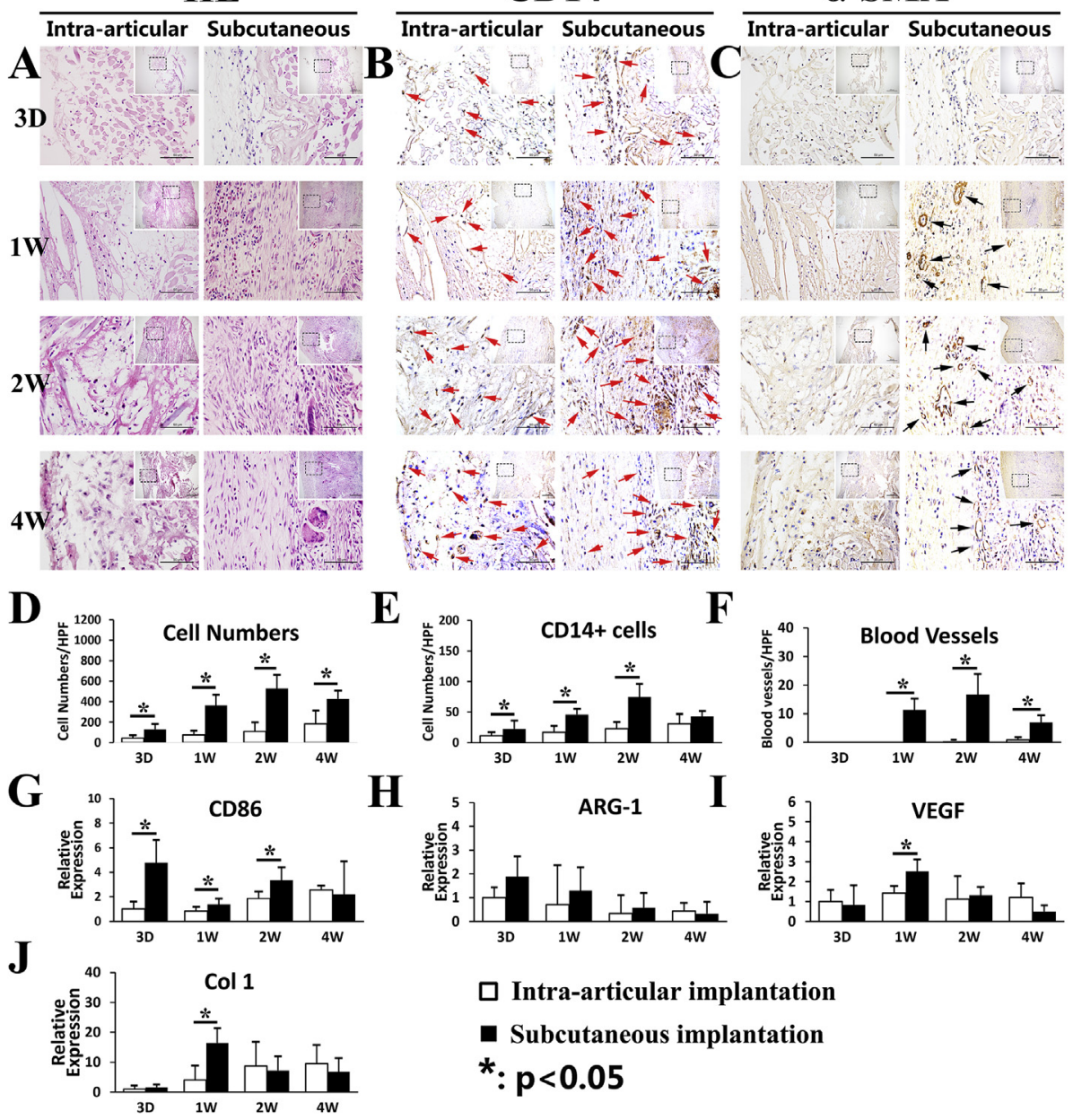

\section{$\square$ Intra-articular implantation \\ - Subcutaneous implantation \\ $*: p<0.05$}

Fig. 1. Comparison of inflammatory response and neo-tissue ingrowth in the silk collagen scaffold between intra- and extra-articular implantation. (A) HE staining; (B-C) IHC staining against CD14 and a-SMA, respectively. Red arrow: CD14 positive cells; Black arrow: blood vessels. (D-F) Quantification of total cells, CD14 positive cells and blood vessels in each high power field. (G-J) RT-PCR analysis of CD86, ARG-1, VEGF and Col 1. ${ }^{*}: \mathrm{p}<0.05$. Scale bar $=50 \mu \mathrm{m}, 200 \mu \mathrm{m}$ (inset). Abbreviations: a-SMA: alpha smooth muscle actin; HPF: High-power field. ARG-1: arginase 1; VEGF: vascular endothelial growth factor; Col 1: collagen type 1.

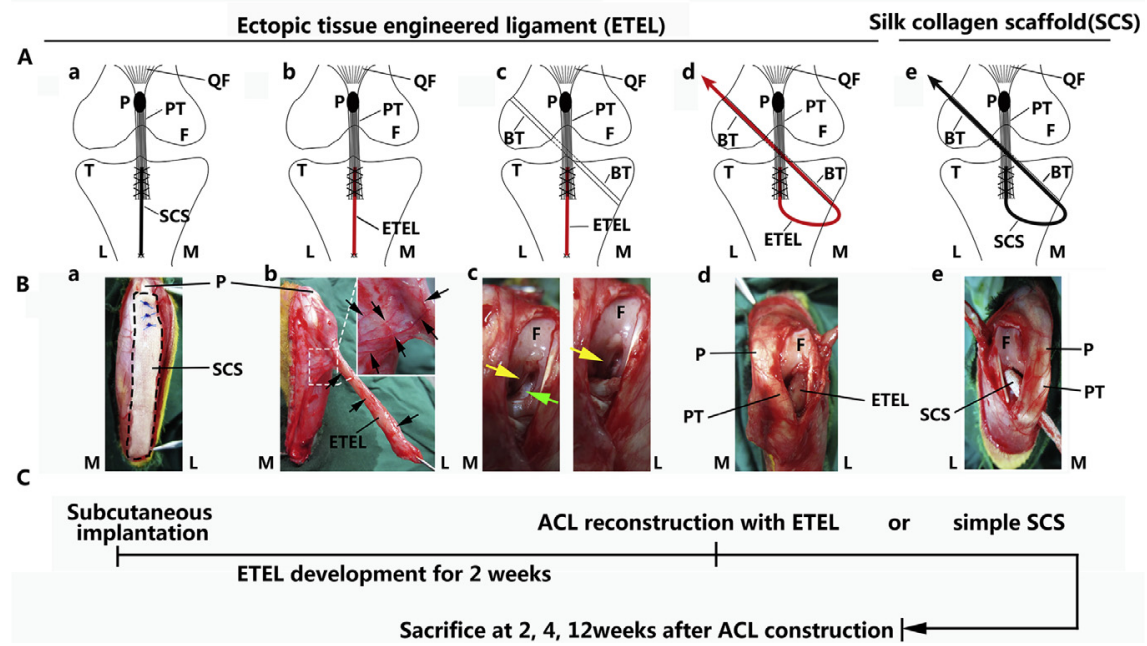

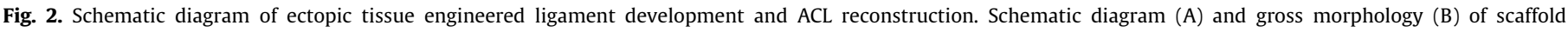

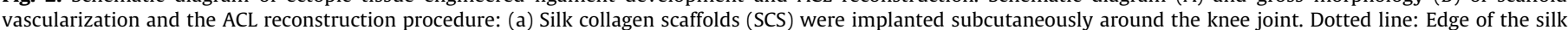

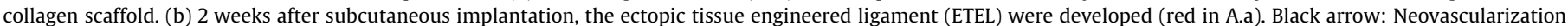

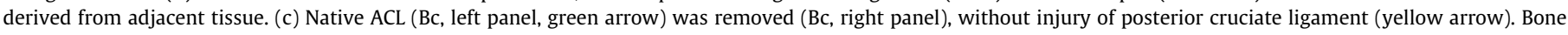

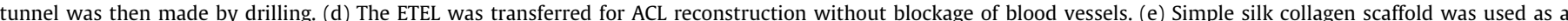

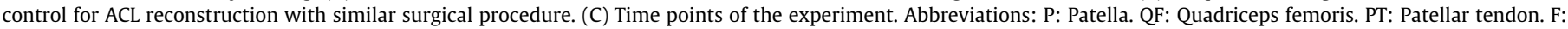

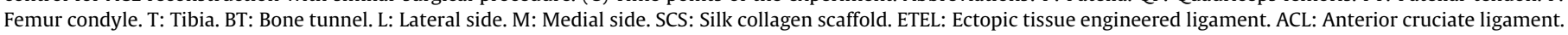



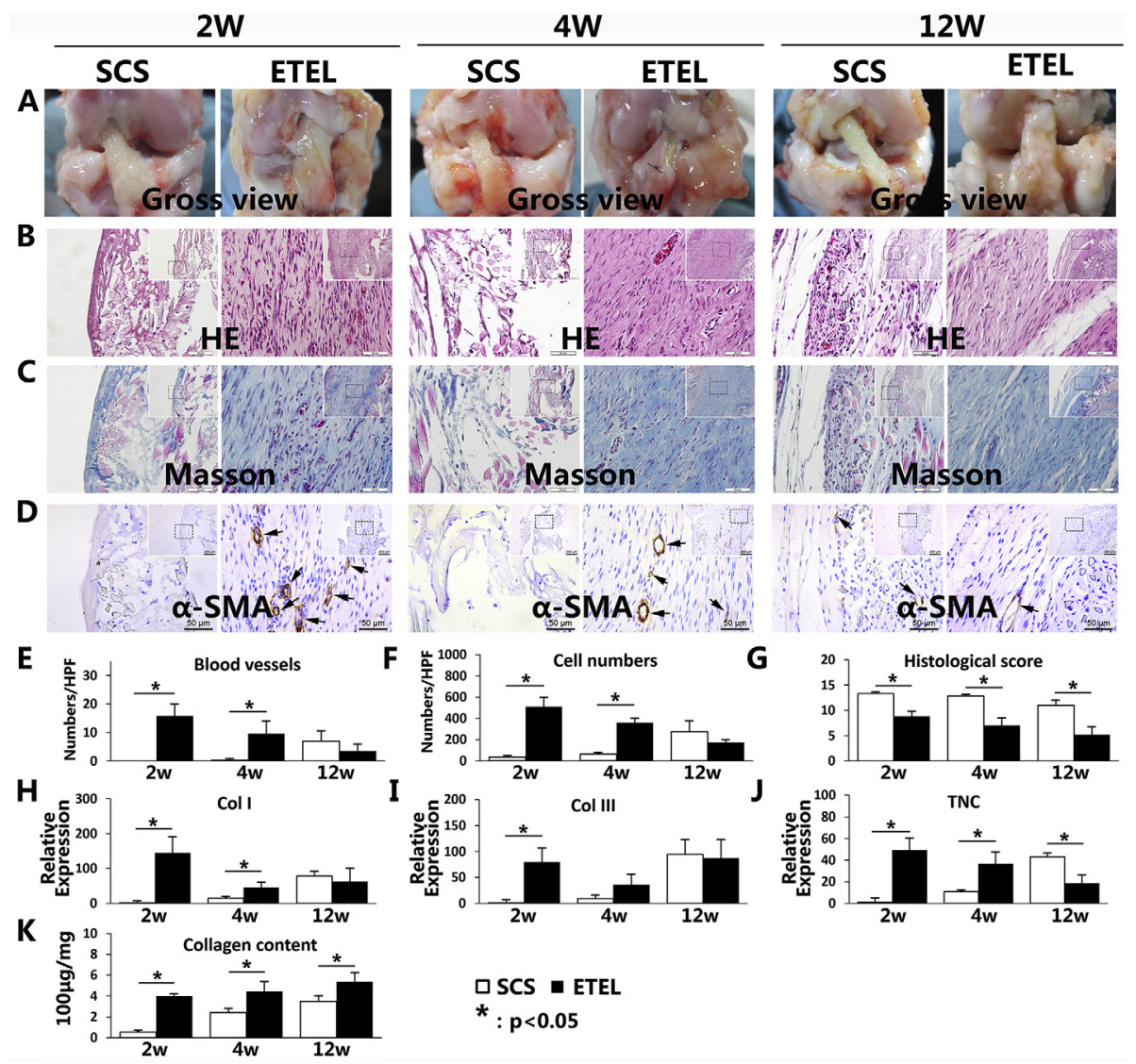

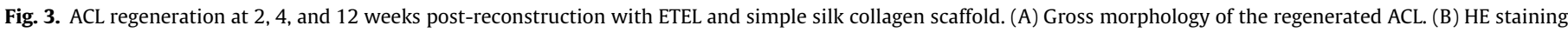

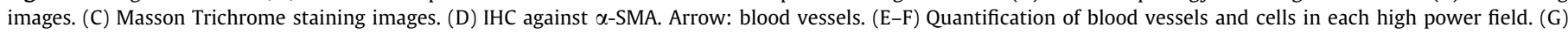

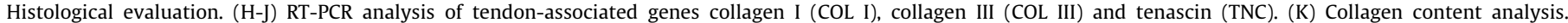

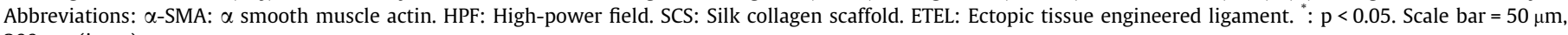
$200 \mu \mathrm{m}$ (inset).

Masson trichrome staining showed that in the ETEL group, the collagen content increased and the collagen fiber arrangement was aligned in a parallel manner, indicating collagen maturation with prolonged duration. In contrast, in the SCS group, collagen deposition was less than the ETEL group at all time-points (Fig. 3C). Further quantitative analysis demonstrated that the ETEL group promoted more collagen deposition than the SCS group at all time-points (Fig. 3K). Additionally, gene expression levels of ligament repair markers including Col I, Col III, and TNC was higher than the SCS group at early stages (Fig. $3 \mathrm{H}-\mathrm{J}$ ).

\subsection{ETEL enhanced collagen fibril formation and maturation}

The reconstruction and maturation of regenerated ACL are evident by the formation of collagen fibrils. Hence, we evaluated collagen fibril formation with polarized light microscopy (Fig. 4) and transmission electron microscopy (TEM) (Fig. 5). In the SCS group, only a few dispersed fibrils could be observed under polarized light microscopy at 12 weeks post-reconstruction (Fig. 4A, C, E, white arrow). In contrast, in the ETEL group, collagen fibrils could be detected at 2 weeks post-reconstruction and became more continuous and transparent at 4 weeks and 12 weeks post-reconstruction (Fig. 4B, D, F, red arrow).

TEM imaging from the cross-section revealed denser and larger fibril formation in the ETEL group, as compared to the patched, sparse and thin fibrils observed in the SCS group (Fig. 5A). In longitudinal section TEM imaging, collagen fibrils were observed to be more organized and compact in the ETEL group compared to the
SCS group at all time points (Fig. 5B). In the ETEL group, the distribution of collagen fibrils exhibited a dramatic remodeling process, which exhibited a large-small pattern in 2 weeks resulting from the newly-formed fibril production, and which turned into a homogeneous pattern in 12 weeks with new fibrils growing stronger (Fig. 5A,E, F). In contrast, the fibril distribution of the SCS group presented a classic regenerative pattern with increased collagen fibril diameter and density as time progresses (Fig. 5A, C, D). Additionally, the quantification analysis demonstrated a significantly lager fibril diameter in the ETEL group, as compared to the SCS group at week 2 and 12 (Fig. 5G).

\subsection{ETEL enhanced ligament-bone integration}

Besides ACL regeneration, we also evaluated the effects of the ETEL on ligament-bone junction regeneration. At 2 weeks postreconstruction, more fibrous connective tissue was present between the host bone and the scaffold in the ETEL group, as compared to the SCS group (Fig. 6 A, Fig. S2A). At 4 and 12 weeks post-reconstruction, a typical ligament-bone interface with the integration of fibrocartilage layers was generated in the ETEL group (Fig. 6 B\&C, black arrow; Fig. S2 B\&C), whereas no fibrocartilaginous tissue was formed in the SCS group. In the SCS group, the MRI analysis revealed a high signal gap around the scaffold in the T2 phase at 12 weeks post-reconstruction (Fig. 6D\&E, red arrow), indicating a poor union of the scaffold with the bone tissue. On the reverse, no obvious gap was detected between the ETEL and the host bone. In the microCT analysis, more mineralized tissue 

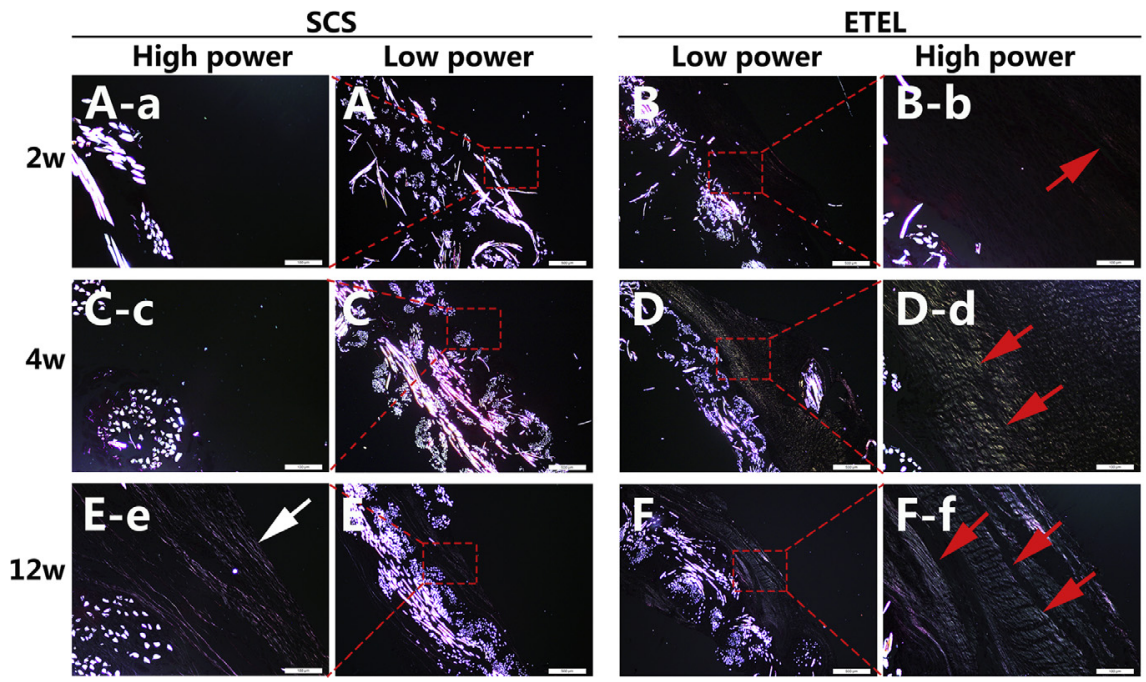

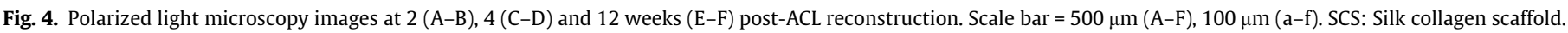
White and red arrows: Mature collagen fibers. Abbreviations: SCS: Silk collagen scaffold. ETEL: Ectopic tissue engineered ligament.

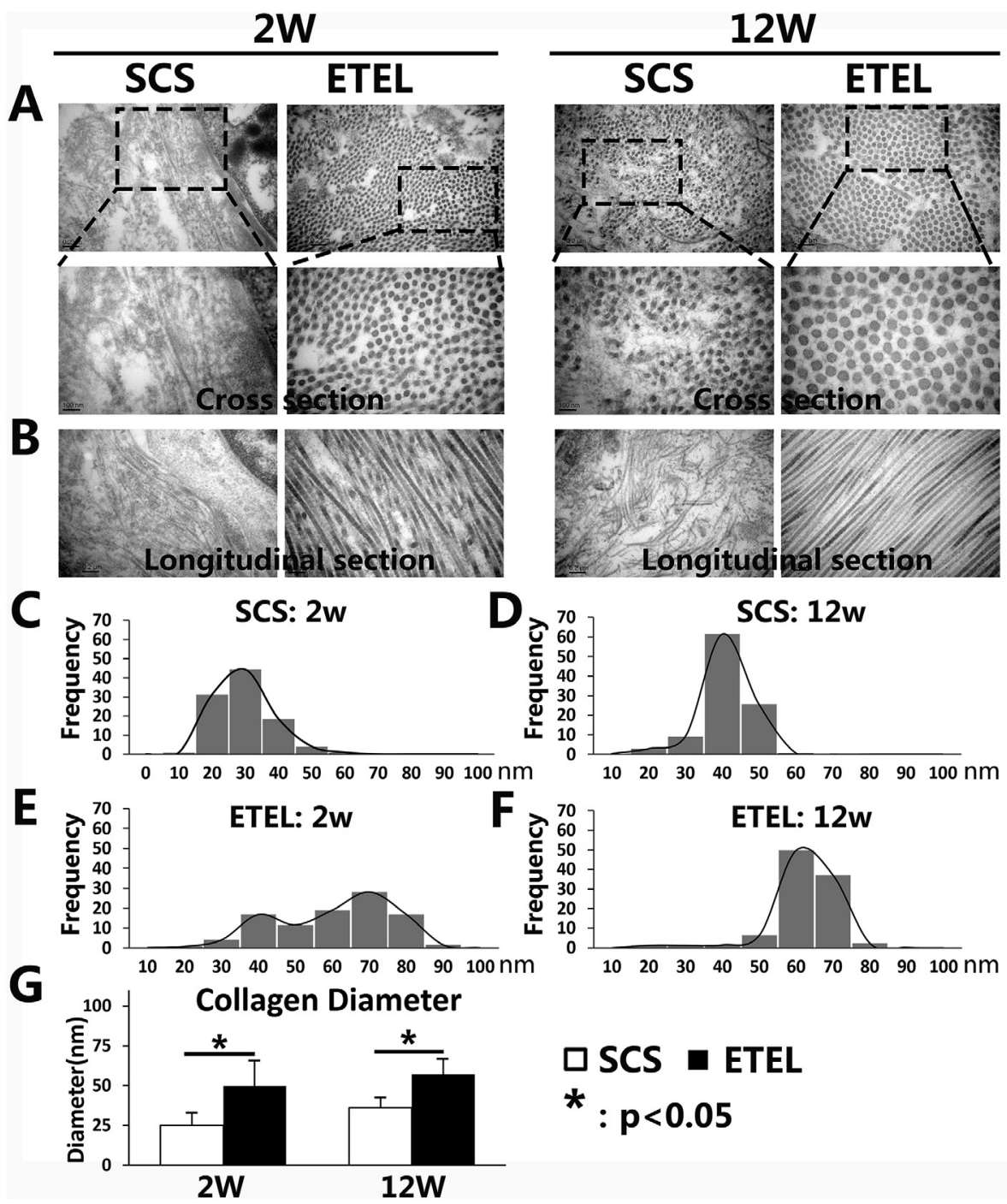

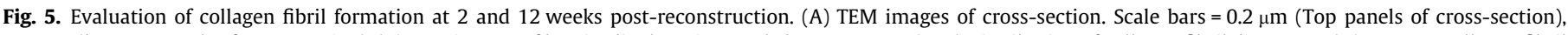

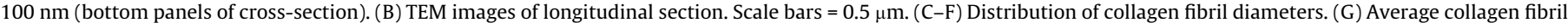
diameter. ": P < 0.05. Abbreviations: SCS: Silk collagen scaffold. ETEL: Ectopic tissue engineered ligament. 




Fig. 6. Assessment of regenerative ligament-bone integration. Safranin O staining images at 2 (A), 4 (B) and 12 weeks post-reconstruction. Scale bars $=200 \mu \mathrm{m}$, $500 \mu \mathrm{m}$ (inset). (C). Black arrow: cartilage formation. (D-E) MRI images from the vertical plane (D) and horizontal plane (E) in the T2 phase for samples at 12 weeks post-reconstruction. Dotted curve: Outer line of femur condyle. White star: regenerative scaffold. Red arrow: High signal was present around the scaffold, indicating a gap filled full with joint fluid. (E) Reconstructed image of microCT analysis for samples at 12 weeks post-operation. Abbreviations: SCS: Silk collagen scaffold. ETEL: Ectopic tissue engineered ligament. (For interpretation of the references to colour in this figure legend, the reader is referred to the web version of this article.)

was found in the bone tunnel of the ETEL group, as compared to the SCS group (Fig. 6F).

\subsection{ETEL exhibited better mechanical properties}

The mechanical test were also carried out to evaluate the function of ACL regeneration at 12 weeks post regenerative surgery. As illustrated in Fig. 7A, the load-elongation curves were tall and steep in the ETEL group whereas those were laigh and elongated in the SCS group. The stiffness and modulus were significantly higher in the ETEL group than the SCS group (21.60 \pm 7.30 vs. $7.02 \pm 1.93 \mathrm{~N} / \mathrm{mm}$ and $49.49 \pm 10.14$ vs. $17.12 \pm 1.89 \mathrm{MPa}$, respectively; $n=3, p<0.05$ for both) (Fig. $7 \mathrm{~B}$ ). The maximal load of regenerated ACL in ETEL group were 78.3\% higher than that in the SCS group, but the difference was not significant. This may due to the relatively small sample size $(n=3)$.

\section{Discussion}

Surgical reconstruction of a functional ACL after injury remains a formidable clinical challenge. In this study, we created a new ETEL based on our previous study. ETEL overcame the lack of initial inflammatory response and cellularity within the joint cavity and promoted ACL regeneration with more ECM deposition, enhanced collagen fibril maturation, larger collagen fibril diameters and increased expression of ligament-associated genes, as well as improved ligament-bone healing and mechanical properties. Hence, it is evident that the vascularized ETEL is a promising biomaterial construct for ligament tissue engineering and clinical treatment of ACL injuries.

It is well-known that the regenerative process of the intraarticular ACL is markedly prolonged compared to MCL $[13,15]$. The differences in microenvironment and inflammatory response maybe a major reason for the different early regenerative outcomes of ACL versus MCL. The inflammatory response after ACL injury was demonstrated to be relatively mild compared to $\mathrm{MCL}$ injury, as evidenced by an absence of wound site filling, paucity of inflammatory cells and dramatically decreased presence of important extracellular matrix proteins and cytokines within the ACL wound site [45-47]. In accordance with the histological results of ACL injury, in this present study, we demonstrated that the early inflammatory response during scaffold based tissue engineering was also markedly different between the intra- and extraarticular microenvironment. CD14 positive monocytes/macrophages recruitment, pro-angiogenic factor VEGF gene expression, vascularization and neo-tissue ingrowth in the subcutaneously implanted scaffolds were far greater than the intra-articular scaffold (Fig. 1). Hence, based on this finding, we further developed a novel strategy to avoid the poor early inflammatory response in the intra-articular environment and accelerate the early ingrowth of endogenous cells and micro vessels into the silk collagen scaffold by preliminarily implanting the silk collagen scaffold in an ectopic subcutaneous pocket. After transferring the ectopic tissue engineered ligament into the joint cavity for ACL reconstruction, abundant well-perfused cells were preserved within the scaffold, which gradually decreased in number in the intra-articular environment with ligament maturation.

Autografts and allografts are the most common graft types utilized to surgically reconstruct ACL at present. The healing procedure with grafting has been demonstrated by in vivo and in vitro studies to have three characteristic stages: an early graft healing phase with central graft necrosis, hypocellularity with no detectable revascularization, followed by a highly intensive revascularization and remodeling phase with cell infiltration and proliferation, and finally a ligamentization phase with characteristic remodeling of the graft towards the properties of intact ACL [48]. Although normal tendon/ligaments exhibit an avascular or hypovascular structure and neovascularization is always related to tendinopathy or injuries, revascularization is a key process to initiate cell ingrowth and matrix remodeling during ACL reconstruction. The remnant preserving technique, which provides more blood vessels and proprioceptive tissues, is demonstrated to result in increased ligamentization, ligament-bone integration and 

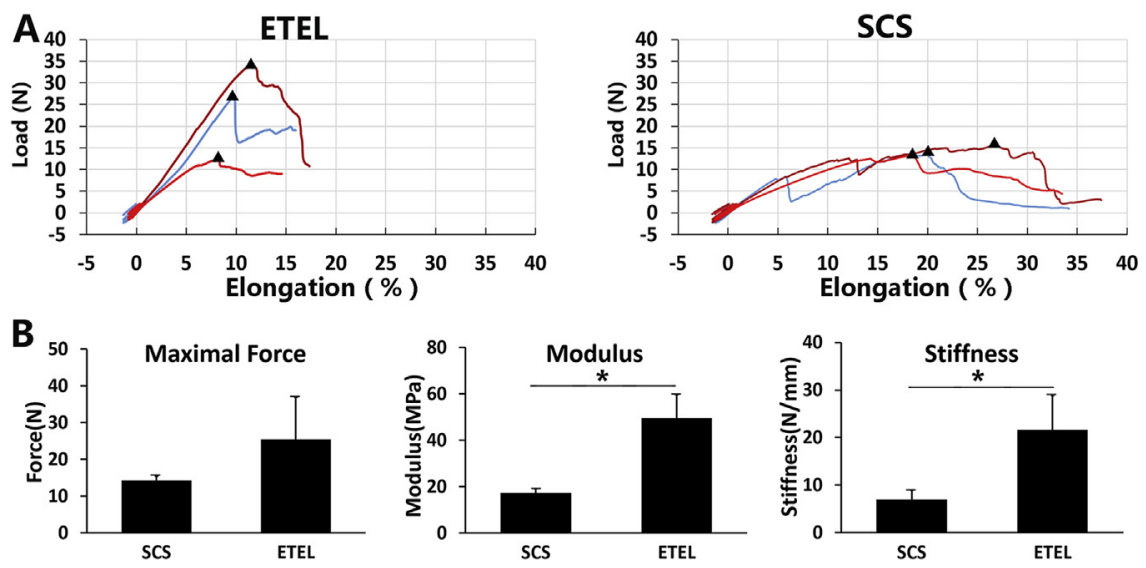

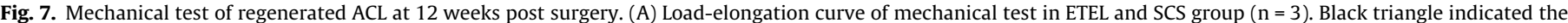

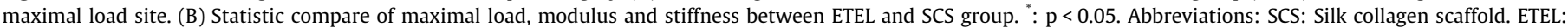
Ectopic tissue engineered ligament.

mechanical strength in animals [49-51]. By contrast, the delay or failure of vascularization is always associated with bad ligamentbone healing and insufficient ligament maturation, which may result in reconstruction failure as manifested by graft rupture and joint laxity $[52,53]$.

Adequate vascularization is also essential for tendon/ligament development, repair and regeneration. During development, tendons are highly plastic tissues in fetus with high cellularity and vascularity, which decrease with tendon maturation [54,55]. Although over-expression of vascular endothelial growth factor (VEGF) has been shown to impede improvements in biomechanical strength after ACL regeneration, blocking VEGF significantly reduced angiogenesis, graft maturation and biomechanical strength [56]. Despite a supportive role in delivering oxygen and nutrients, the perivascular cells have been demonstrated to play an important role in contributing to mesoderm tissue growth and repair but will result in pathological fibrosis if overstimulated [57-60]. These previous studies emphasized the requirement for proper dynamic vascularity during ACL regeneration. In this study, we developed a highly vascularized and cellular plastic scaffold, which exhibited reduction in cell numbers and blood vessels after being implanted for ACL reconstruction, which mimicked the natural tendon development process and resulted in a hypovascular structure with parallel cells and fibers within 12 weeks. The characteristics of the regenerated ACL, including gross morphology, cell shape, ECM accumulation and collagen microstructure were more similar to native ACL in the ETEL group than the SCS group, which contributed to better biomechanical properties in the ETEL group. Although the mechanism of the vascular decrease is not clear, the mechanically-induced downregulation of VEGF expression may be a possible reason [61].

Besides ACL regeneration per se, the ligament-bone integration is also important for effective ACL reconstruction, by enabling earlier and robust rehabilitation and to prevent long-term OA occurrence due to ligament tear or joint laxity. Firm ligament-bone integration can be achieved by the direct osteointegration of the tendon graft, which resembles the normal chondral entities of ACL and which has been proven to be biomechanically stronger than the indirect connection by Sharpey-like collagen fibers [62]. To enhance this process, a variety of bioactive techniques have been developed, consisting mainly of growth factor release and stem cell transplantation. A number of growth factors with osteoinductive activity, such as bone morphogenetic proteins (BMPs) [63,64] and transforming growth factors (TGF) [65], have been applied to enhance ligament-bone integration and result in more favorable outcomes. Additionally, the pro-angiogenic fator
VEGF, which can synergize with BMP2 to promote bone formation and bone healing via modulation of angiogenesis [66,67], can also promote ACL-bone integration as well [68]. On the other hand, bone marrow mesenchymal stem cells (MSCs), with their ability to differentiate into muscle, tendon, cartilage and bone, have also been widely used to augment ligament bone healing [69,70]. Besides MSCs, blood vessels also have a rich supply of stem/ progenitor cells that display characteristic expression of CD34 surface markers [71,72]. Human ACL-derived CD34+ cells have been demonstrated to contribute to tendon-bone healing after ACL reconstruction in a rat model [73]. In this study, high expression levels of the angiogenesis-associated factor VEGF coupled with the presence of multi-potential regenerative cells maybe the reasons for the enhanced formation of fibrocartilage and mineralized bone formation within the bone tunnel.

Our study thus provided a step-wise strategy for ACL reconstruction with a self-assembly phase to generate a vascularized TE ligament before reconstructive surgery. This strategy contributed to efficacious ligament regeneration and ligament-bone healing, thus indicating promising potential for clinical translation. The patients themselves can be employed as a "physiological incubator" and the generated ectopic TE ligament contains autologous regenerative cells within a neo-vascularized and highlybiocompatible silk collagen scaffold. This scaffold based procedure negates the requirement for autologous, allogeneic and xenogenic ligament grafts, thus avoiding the risk of disease transmission and donor site morbidity. However, the requirement for two surgical procedures, which may increase patients' discomfort and medical costs, are the key drawbacks of its clinical translation.

Nevertheless, there are still some limitations to our study. We used rabbits as a proof-of-concept model which may not fully mimic human physiological and mechanical conditions. The limited number of experimental animals may not represent enough evidence, too. Big animal models, such as pig and sheep, may be needed for further evaluation before the onset of clinical trials.

\section{Conclusion}

In summary, this study developed a vascularized ectopic tissue engineered ligament with silk collagen scaffold. The tissue engineered ligament not only enhanced ACL regeneration, but also promoted ligament-bone healing and offered better mechanical properties. This result highlights the importance of sufficient early-stage perfusion and cells in ACL regeneration. Our work thus provide valuable insight for future ligament tissue engineering studies and clinical practice. 


\section{Acknowledgment}

This work was supported by NSFC Grants (81330041, 81125014, 31271041, 81201396, 81271970, J1103603, 81572115, 81572157, 81572173, 81371996), The National Key Scientific Program (2012CB966604), The National High Technology Research and Development Program of China (863 Program) (No. 2012AA020503), Regenerative Medicine in Innovative Medical Subjects of Zhejiang Province and Zhejiang Provincial Program for the Cultivation of High-Level Innovative Health Talents, Zhejiang Province Grants (Z2100086, LY12H06006, LR14H060001, LY14H060002 LY14H060003), Medical and Health Science and Technology Plan of the Department of Health of Zhejiang Province (2013RCA010, 2014KYB052), Medical Science and Technology Project of Zhejiang Province (201341741), and Zhejiang Provisional Grant (2012C33015). The authors would like to acknowledge valuable assistance rendered by the staff of the Animal Research Center of Zhejiang University and the Analysis and Measurement Center of Agrobiology and Environment, Zhejiang University. None of the authors had professional or financial affiliations that could potentially bias this study.

\section{Appendix A. Supplementary data}

Supplementary data associated with this article can be found, in the online version, at http://dx.doi.org/10.1016/j.actbio.2017.02. 027.

\section{References}

[1] C.R. LaBella, W. Hennrikus, T.E. HewettCouncil on Sports M, Fitness, Section on $\mathrm{O}$, Anterior cruciate ligament injuries: diagnosis, treatment, and prevention, Pediatrics 133 (2014) e1437-e1450.

[2] H.S. Kim, J.K. Seon, A.R. Jo, Current trends in anterior cruciate ligament reconstruction, Knee Surg. Related Res. 25 (2013) 165-173.

[3] R. Vaishya, A.K. Agarwal, S. Ingole, V. Vijay, Current trends in anterior cruciate ligament reconstruction: a review, Cureus (2015).

[4] O.S. Schindler, Surgery for anterior cruciate ligament deficiency: a historical perspective, Knee Surg. Sports Traumatol. Arthrosc. 20 (2012) 5-47.

[5] B.D. Smith, D.A. Grande, The current state of scaffolds for musculoskeletal regenerative applications, Nat. Rev. Rheumatol. 11 (2015) 213-222.

[6] H. Tohyama, T. Yoshikawa, Y.J. Ju, K. Yasuda, Revascularization in the tendon graft following anterior cruciate ligament reconstruction of the knee: its mechanisms and regulation, Chang Gung Med. J. 32 (2009) 133-139.

[7] H. Kanamura, Y. Arai, K. Hara, T. Takahashi, K. Ikoma, H. Fujiwara, G. Minami, R. Terauchi, S. Nakagawa, K. Honjo, T. Kubo, Quantitative evaluation of revascularization at bone tunnels and grafts with contrast-enhanced magnetic resonance angiography after anterior cruciate ligament reconstruction, Int. Orthop. (2016).

[8] R. Terauchi, Y. Arai, K. Hara, G. Minami, S. Nakagawa, T. Takahashi, K. Ikoma, K. Ueshima, T. Shirai, H. Fujiwara, T. Kubo, Magnetic resonance angiography evaluation of the bone tunnel and graft following ACL reconstruction with a hamstring tendon autograft, Knee Surg. Sports Traumatol. Arthrosc. 24 (2016) $169-175$.

[9] T. Nau, A. Teuschl, Regeneration of the anterior cruciate ligament: current strategies in tissue engineering, World J. Orthopedics 6 (2015) 127-136.

[10] S. Levenberg, J. Rouwkema, M. Macdonald, E.S. Garfein, D.S. Kohane, D.C. Darland, R. Marini, C.A. van Blitterswijk, R.C. Mulligan, P.A. D’Amore, R. Langer, Engineering vascularized skeletal muscle tissue, Nat. Biotechnol. 23 (2005) $879-884$.

[11] B. Kundu, R. Rajkhowa, S.C. Kundu, X. Wang, Silk fibroin biomaterials for tissue regenerations, Adv. Drug Deliv. Rev. 65 (2013) 457-470.

[12] J.L. Chen, Z. Yin, W.L. Shen, X. Chen, B.C. Heng, X.H. Zou, H.W. Ouyang, Efficacy of hESC-MSCs in knitted silk-collagen scaffold for tendon tissue engineering and their roles, Biomaterials 31 (2010) 9438-9451.

[13] X. Chen, Y.Y. Qi, L.L. Wang, Z. Yin, G.L. Yin, X.H. Zou, H.W. Ouyang, Ligament regeneration using a knitted silk scaffold combined with collagen matrix, Biomaterials 29 (2008) 3683-3692.

[14] W. Shen, J. Chen, Z. Yin, X. Chen, H. Liu, B.C. Heng, W. Chen, H.W. Ouyang, Allogenous tendon stem/progenitor cells in silk scaffold for functional shoulder repair, Cell Transplant. 21 (2012) 943-958.

[15] W. Shen, X. Chen, Y. Hu, Z. Yin, T. Zhu, J. Hu, J. Chen, Z. Zheng, W. Zhang, J. Ran, B.C. Heng, J. Ji, W. Chen, H.W. Ouyang, Long-term effects of knitted silkcollagen sponge scaffold on anterior cruciate ligament reconstruction and osteoarthritis prevention, Biomaterials 35 (2014) 8154-8163.
[16] E.C. Novosel, C. Kleinhans, P.J. Kluger, Vascularization is the key challenge in tissue engineering, Adv. Drug Deliv. Rev. 63 (2011) 300-311.

[17] H. Bae, A.S. Puranik, R. Gauvin, F. Edalat, B. Carrillo-Conde, N.A. Peppas, A. Khademhosseini, Building vascular networks, Sci. Transl. Med. 4 (160p) (2012) s23.

[18] A.H. Zisch, M.P. Lutolf, J.A. Hubbell, Biopolymeric delivery matrices for angiogenic growth factors, Cardiovasc. Pathol. 12 (2003) 295-310.

[19] J.E. Leslie-Barbick, J.J. Moon, J.L. West, Covalently-immobilized vascular endothelial growth factor promotes endothelial cell tubulogenesis in poly (ethylene glycol) diacrylate hydrogels, J. Biomater. Sci. Polym. Ed. 20 (2009) 1763-1779.

[20] M.M. Martino, S. Brkic, E. Bovo, M. Burger, D.J. Schaefer, T. Wolff, L. Gurke, P.S Briquez, H.M. Larsson, R. Gianni-Barrera, J.A. Hubbell, A. Banfi, Extracellular matrix and growth factor engineering for controlled angiogenesis in regenerative medicine, Front. Bioeng. Biotechnol. 3 (2015) 45.

[21] H. Hosseinkhani, M. Hosseinkhani, A. Khademhosseini, H. Kobayashi, Y. Tabata Enhanced angiogenesis through controlled release of basic fibroblast growth factor from peptide amphiphile for tissue regeneration, Biomaterials 27 (2006) $5836-5844$.

[22] J.S. Schechner, A.K. Nath, L. Zheng, M.S. Kluger, C.C. Hughes, M.R. SierraHonigmann, M.I. Lorber, G. Tellides, M. Kashgarian, A.L. Bothwell, J.S. Pober, In vivo formation of complex microvessels lined by human endothelial cells in an immunodeficient mouse, Proc. Natl. Acad. Sci. U.S.A. 97 (2000) 9191-9196.

[23] X. Wu, E. Rabkin-Aikawa, K.J. Guleserian, T.E. Perry, Y. Masuda, F.W Sutherland, F.J. Schoen, J.E. Mayer Jr., J. Bischoff, Tissue-engineered microvessels on three-dimensional biodegradable scaffolds using human endothelial progenitor cells, Am. J. Physiol. Heart Circulatory Physiol. 287 (2004) H480-H487.

[24] B. Gokcinar-Yagci, D. Uckan-Cetinkaya, B. Celebi-Saltik, Pericytes: properties, functions and applications in tissue engineering, Stem Cell Rev. 11 (2015) 549-559.

[25] K.M. Chrobak, D.R. Potter, J. Tien, Formation of perfused, functional microvascular tubes in vitro, Microvasc. Res. 71 (2006) 185-196.

[26] A.P. McGuigan, M.V. Sefton, Vascularized organoid engineered by modular assembly enables blood perfusion, Proc. Natl. Acad. Sci. U.S.A. 103 (2006) $11461-11466$

[27] N. Sadr, M. Zhu, T. Osaki, T. Kakegawa, Y. Yang, M. Moretti, J. Fukuda, A. Khademhosseini, SAM-based cell transfer to photopatterned hydrogels for microengineering vascular-like structures, Biomaterials 32 (2011) 7479-7490.

[28] J.S. Miller, K.R. Stevens, M.T. Yang, B.M. Baker, D.H. Nguyen, D.M. Cohen, E. Toro, A.A. Chen, P.A. Galie, X. Yu, R. Chaturvedi, S.N. Bhatia, C.S. Chen, Rapid casting of patterned vascular networks for perfusable engineered threedimensional tissues, Nat. Mater. 11 (2012) 768-774.

[29] V.K. Lee, D.Y. Kim, H. Ngo, Y. Lee, L. Seo, S.S. Yoo, P.A. Vincent, G. Dai, Creating perfused functional vascular channels using 3D bio-printing technology, Biomaterials 35 (2014) 8092-8102.

[30] A. Tocchio, M. Tamplenizza, F. Martello, I. Gerges, E. Rossi, S. Argentiere, S. Rodighiero, W. Zhao, P. Milani, C. Lenardi, Versatile fabrication of vascularizable scaffolds for large tissue engineering in bioreactor, Biomaterials 45 (2015) 124-131.

[31] T.J. Koh, L.A. DiPietro, Inflammation and wound healing: the role of the macrophage, Expert Rev. Mol. Med. 13 (2011) e23.

[32] B.N. Brown, B.M. Sicari, S.F. Badylak, Rethinking regenerative medicine: a macrophage-centered approach, Front. Immunol. 5 (2014) 510.

[33] B.J. Kwee, D.J. Mooney, Manipulating the intersection of angiogenesis and inflammation, Ann. Biomed. Eng. 43 (2015) 628-640.

[34] A. Fantin, J.M. Vieira, G. Gestri, L. Denti, Q. Schwarz, S. Prykhozhij, F. Peri, S.W Wilson, C. Ruhrberg, Tissue macrophages act as cellular chaperones for vascular anastomosis downstream of VEGF-mediated endothelial tip cell induction, Blood 116 (2010) 829-840.

[35] K.L. Spiller, R.R. Anfang, K.J. Spiller, J. Ng, K.R. Nakazawa, J.W. Daulton, G Vunjak-Novakovic, The role of macrophage phenotype in vascularization of tissue engineering scaffolds, Biomaterials 35 (2014) 4477-4488.

[36] Z. Jiang, L. Zhu, Update on the role of alternatively activated macrophages in asthma, J. Asthma Allergy 9 (2016) 101-107.

[37] M. Karin, H. Clevers, Reparative inflammation takes charge of tissue regeneration, Nature 529 (2016) 307-315.

[38] S. Panayidou, Y. Apidianakis, Regenerative inflammation: lessons from Drosophila intestinal epithelium in health and disease, Pathogens (Basel, Switzerland) 2 (2013) 209-231.

[39] I. Goren, N. Allmann, N. Yogev, C. Schurmann, A. Linke, M. Holdener, A. Waisman, J. Pfeilschifter, S. Frank, A transgenic mouse model of inducible macrophage depletion: effects of diphtheria toxin-driven lysozyme M-specific cell lineage ablation on wound inflammatory, angiogenic, and contractive processes, Am. J. Pathol. 175 (2009) 132-147.

[40] R. Mirza, L.A. DiPietro, T.J. Koh, Selective and specific macrophage ablation is detrimental to wound healing in mice, Am. J. Pathol. 175 (2009) 2454-2462.

[41] J.S. Pieper, A. Oosterhof, P.J. Dijkstra, J.H. Veerkamp, T.H. van Kuppevelt, Preparation and characterization of porous crosslinked collagenous matrices containing bioavailable chondroitin sulphate, Biomaterials 20 (1999) 847858.

[42] P.A. Keblish, The lateral approach to the valgus knee. Surgical technique and analysis of 53 cases with over two-year follow-up evaluation, Clin. Orthop. Relat. Res. (1991) 52-62.

[43] Z. Yin, X. Chen, H.X. Song, J.J. Hu, Q.M. Tang, T. Zhu, W.L. Shen, J.L. Chen, H. Liu, B.C. Heng, H.W. Ouyang, Electrospun scaffolds for multiple tissues 
regeneration in vivo through topography dependent induction of lineage specific differentiation, Biomaterials 44 (2015) 173-185.

[44] Z. Yin, X. Chen, J.L. Chen, W.L. Shen, T.M. Hieu Nguyen, L. Gao, H.W. Ouyang, The regulation of tendon stem cell differentiation by the alignment of nanofibers, Biomaterials 31 (2010) 2163-2175.

[45] M.M. Murray, K.P. Spindler, P. Ballard, T.P. Welch, D. Zurakowski, L.B. Nanney, Enhanced histologic repair in a central wound in the anterior cruciate ligament with a collagen-platelet-rich plasma scaffold, J. Orthopaedic Res. 25 (2007) 1007-1017.

[46] S.L. Woo, T.M. Vogrin, S.D. Abramowitch, Healing and repair of ligament injuries in the knee, J. Am. Acad. Orthopaedic Surgeons 8 (2000) 364-372.

[47] M.M. Murray, Current status and potential of primary ACL repair, Clin. Sports Med. 28 (2009) 51-61.

[48] R.P. Janssen, S.U. Scheffler, Intra-articular remodelling of hamstring tendon grafts after anterior cruciate ligament reconstruction, Knee Surg. Sports Traumatol. Arthrosc. 22 (2014) 2102-2108.

[49] L. Sun, B. Wu, M. Tian, B. Liu, Y. Luo, Comparison of graft healing in anterior cruciate ligament reconstruction with and without a preserved remnant in rabbits, Knee 20 (2013) 537-544.

[50] B. Wu, Z. Zhao, S. Li, L. Sun, Preservation of remnant attachment improves graft healing in a rabbit model of anterior cruciate ligament reconstruction, Arthroscopy 29 (2013) 1362-1371.

[51] H. Li, J. Chen, S. Chen, Remnant repair-enhanced polyethylene terepthalate artificial ligament graft ligamentization, Int. J. Sports Med. 36 (2015) 10151020.

[52] G.V. Kamath, J.C. Redfern, P.E. Greis, R.T. Burks, Revision anterior cruciate ligament reconstruction, Am. J. Sports Med. 39 (2011) 199-217.

[53] R. Mayr, R. Rosenberger, D. Agraharam, V. Smekal, R. El Attal, Revision anterior cruciate ligament reconstruction: an update, Arch. Orthop. Trauma Surg. 132 (2012) 1299-1313.

[54] E.E. Peacock Jr., A study of the circulation in normal tendons and healing grafts, Ann. Surg. 149 (1959) 415-428.

[55] V. Russo, A. Mauro, A. Martelli, O. Di Giacinto, L. Di Marcantonio, D. Nardinocchi, P. Berardinelli, B. Barboni, Cellular and molecular maturation in fetal and adult ovine calcaneal tendons, J. Anat. 226 (2015) 126-142.

[56] K. Takayama, Y. Kawakami, Y. Mifune, T. Matsumoto, Y. Tang, J.H. Cummins, N. Greco, R. Kuroda, M. Kurosaka, B. Wang, F.H. Fu, J. Huard, The effect of blocking angiogenesis on anterior cruciate ligament healing following stem cell transplantation, Biomaterials 60 (2015) 9-19.

[57] A. Armulik, G. Genove, C. Betsholtz, Pericytes: developmental, physiological, and pathological perspectives, problems, and promises, Dev. Cell 21 (2011) 193-215.

[58] O. Cappellari, G. Cossu, Pericytes in development and pathology of skeletal muscle, Circ. Res. 113 (2013) 341-347.

[59] S.P. Wong, J.E. Rowley, A.N. Redpath, J.D. Tilman, T.G. Fellous, J.R. Johnson, Pericytes, mesenchymal stem cells and their contributions to tissue repair Pharmacol. Ther. 151 (2015) 107-120.

[60] L. Worthley Daniel, M. Churchill, T. Compton Jocelyn, Y. Tailor, M. Rao, Y. Si, D. Levin, G. Schwartz Matthew, A. Uygur, Y. Hayakawa, S. Gross, W. Renz Bernhard, W. Setlik, N. Martinez Ashley, X. Chen, S. Nizami, G. Lee Heon, H.P. Kang, J.-M. Caldwell, S. Asfaha, C.B. Westphalen, T. Graham, G. Jin, K. Nagar, H. Wang, A. Kheirbek Mazen, A. Kolhe, J. Carpenter, M. Glaire, A. Nair, S. Renders,
N. Manieri, S. Muthupalani, G. Fox James, M. Reichert, S. Giraud Andrew, F. Schwabe Robert, J.-P. Pradere, K. Walton, A. Prakash, D. Gumucio, K. Rustgi Anil, S. Stappenbeck Thaddeus, A. Friedman Richard, D. Gershon Michael, P. Sims, T. Grikscheit, Y. Lee Francis, G. Karsenty, S. Mukherjee, Timothy C. Wang, Gremlin 1 identifies a skeletal stem cell with bone, cartilage, and reticular stromal potential, Cell 160 (2015) 269-284.

[61] W. Petersen, T. Pufe, B. Kurz, R. Mentlein, B. Tillmann, Angiogenesis in fetal tendon development: spatial and temporal expression of the angiogenic peptide vascular endothelial cell growth factor, Anat. Embryol. 205 (2002) 263-270.

[62] C.H. Chen, Strategies to enhance tendon graft-bone healing in anterior cruciate ligament reconstruction, Chang Gung Med. J. 32 (2009) 483-493.

[63] S.A. Rodeo, K. Suzuki, X.H. Deng, J. Wozney, R.F. Warren, Use of recombinant human bone morphogenetic protein-2 to enhance tendon healing in a bone tunnel, Am. J. Sports Med. 27 (1999) 476-488.

[64] R. Mihelic, M. Pecina, M. Jelic, S. Zoricic, V. Kusec, P. Simic, D. Bobinac, B. Lah, D. Legovic, S. Vukicevic, Bone morphogenetic protein-7 (osteogenic protein-1) promotes tendon graft integration in anterior cruciate ligament reconstruction in sheep, Am. J. Sports Med. 32 (2004) 1619-1625.

[65] S. Yamazaki, K. Yasuda, F. Tomita, H. Tohyama, A. Minami, The effect of transforming growth factor-beta1 on intraosseous healing of flexor tendon autograft replacement of anterior cruciate ligament in dogs, Arthroscopy 21 (2005) 1034-1041.

[66] H. Peng, V. Wright, A. Usas, B. Gearhart, H.C. Shen, J. Cummins, J. Huard, Synergistic enhancement of bone formation and healing by stem cellexpressed VEGF and bone morphogenetic protein-4, J. Clin. Investig. 110 (2002) 751-759.

[67] H. Peng, A. Usas, A. Olshanski, A.M. Ho, B. Gearhart, G.M. Cooper, J. Huard, VEGF improves, whereas sFlt1 inhibits, BMP2-induced bone formation and bone healing through modulation of angiogenesis, J. Bone Mineral Res. 20 (2005) 2017-2027.

[68] A.E. Al Subaie, H. Eimar, M.N. Abdallah, R. Durand, J. Feine, F. Tamimi, E. Emami, Anti-VEGFs hinder bone healing and implant osseointegration in rat tibiae, J. Clin. Periodontol. 42 (2015) 688-696.

[69] J.K. Lim, J. Hui, L. Li, A. Thambyah, J. Goh, E.H. Lee, Enhancement of tendon graft osteointegration using mesenchymal stem cells in a rabbit model of anterior cruciate ligament reconstruction, Arthroscopy 20 (2004) 899-910.

[70] H.W. Ouyang, J.C. Goh, E.H. Lee, Use of bone marrow stromal cells for tendon graft-to-bone healing: histological and immunohistochemical studies in a rabbit model, Am. J. Sports Med. 32 (2004) 321-327.

[71] K.M. Howson, A.C. Aplin, M. Gelati, G. Alessandri, E.A. Parati, R.F. Nicosia, The postnatal rat aorta contains pericyte progenitor cells that form spheroidal colonies in suspension culture, Am. J. Physiol. Cell Physiol. 289 (2005) C1396C1407.

[72] E. Zengin, F. Chalajour, U.M. Gehling, W.D. Ito, H. Treede, H. Lauke, J. Weil, H. Reichenspurner, N. Kilic, S. Ergun, Vascular wall resident progenitor cells: a source for postnatal vasculogenesis, Development 133 (2006) 1543-1551.

[73] Y. Mifune, T. Matsumoto, S. Ota, M. Nishimori, A. Usas, S. Kopf, R. Kuroda, M. Kurosaka, F.H. Fu, J. Huard, Therapeutic potential of anterior cruciate ligamentderived stem cells for anterior cruciate ligament reconstruction, Cell Transplant. 21 (2012) 1651-1665. 